九州大学学術情報リポジトリ

Kyushu University Institutional Repository

\title{
The Influence of Pore Size and Material Properties on Biomechanical Analysis of Parietal-Temporal Implant
}

Wan Nur Fatini Syahirah W. Dagang

School of Mechanical Engineering, College of Engineering, Universiti Teknologi MARA (UiTM)

Shahrul Hisyam Marwan

School of Mechanical Engineering, College of Engineering, Universiti Teknologi MARA (UiTM) Terengganu Branch, Bukit Besi Campus

Mahmud, Jamaludd in

School of Mechanical Engineering, College of Engineering, Universiti Teknologi MARA (UiTM)

Nor Fazli Adull Manan

School of Mechanical Engineering, College of Engineering, Universiti Teknologi MARA (UiTM)

他

https://doi.org/10.5109/4742118

出版情報 : Evergreen. 8 (4)，pp.750-758，2021-12. 九州大学グリーンテクノロジー研究教育センター バージョン：

権利関係 : 


\title{
The Influence of Pore Size and Material Properties on Biomechanical Analysis of Parietal-Temporal Implant
}

\author{
Wan Nur Fatini Syahirah W. Dagang1, Shahrul Hisyam Marwan², \\ Jamaluddin Mahmud ${ }^{1}$, Nor Fazli Adull Manan ${ }^{1}$, Abdul Halim Abdullah ${ }^{1, *}$ \\ ${ }^{1}$ School of Mechanical Engineering, College of Engineering, Universiti Teknologi MARA (UiTM), \\ 40450 Shah Alam, Selangor, Malaysia. \\ ${ }^{2}$ School of Mechanical Engineering, College of Engineering, Universiti Teknologi MARA (UiTM) \\ Terengganu Branch, Bukit Besi Campus, 23200 Dungun, Terengganu, Malaysia. \\ *Author to whom correspondence should be addressed: \\ E-mail: halim471@uitm.edu.my
}

(Received July 27, 2021; Revised October 24, 2021; accepted October 26, 2021).

\begin{abstract}
This study aimed to analyze the biomechanical behavior of the cranial implant by varying materials (titanium, hydroxyapatite, and zinc-hydroxyapatite) and pore size (600, 900, and $1200 \mu \mathrm{m})$ through a finite element method since there is a lack of study on this area. The cranial implant was reconstructed from the DICOM images, and the biomechanical behavior was evaluated in terms of Von Mises stress and deformation. The maximum Von Mises stress was primarily influenced by pore size in this study. Meanwhile, the material properties had the greatest influence on the implant's deformation. Subsequently, the safety factor was considered, and titanium implant with a pore size of $900 \mu \mathrm{m}$ showed excellent results.
\end{abstract}

Keywords: Finite element analysis; biomechanical analysis; cranioplasty; cranial implant, 3D model; pore size

\section{Introduction}

A cranial defect could be occurred because of falls, vehicle crashes, assaults, and any sport-related events such as hockey, rugby, and baseball. Mostly, the head injury happened at the parietal-temporal; the best location as the real pedestrian accidents ${ }^{1)}$ and sport-related accidents include crickets $^{2)}$, baseball and softballs ${ }^{3)}$ impacted on the head. The cranioplasty operation will take place to repair the cranial defect. Cranioplasty has been remarkably successful in restoring the cosmetic appearance and restoring the primary function of the skull, which is to protect the brain for a patient with a cranial defect. In addition, cranioplasty operation is not only restricted to the skull defect, it is also involved after decompressive craniectomy for traumatic brain injury, intracranial tumor surgery, stroke, and intracranial infections $^{4-6)}$.

The cranioplasty was performed by using autogenous bone or synthetic materials. Both techniques have their pros and cons. The cranioplasty operation with autogenous bone was an excellent way because it has fewer complications of infections. Still, it is limited due to the tissue harvesting problem, finding suitable donor sites, and expensive surgery ${ }^{7}$. Because of that, the use of synthetic materials, either metal, polymers, or ceramics such as aluminum, gold, silver, tantalum, titanium (Ti6Al4V), polymethyl methacrylate (PMMA), polyether ether ketone (PEEK), calcium phosphate (CaP), and hydroxyapatite (HA) were vigorously studied by many researchers ${ }^{4,8-10)}$.

Currently, titanium is dominant for metal materials because it has good strength, biocompatibility, and little infection rate. However, it has a weakness which is poor malleability ${ }^{11)}$. Meanwhile, for ceramic, hydroxyapatite has the advantages of good osseointegration, minimal tissue reaction, and increased bone repair. Still, the main disadvantages of it are low resistance to mechanical stress and can easily break ${ }^{12)}$. Therefore, a potential material that could overcome this critical issue is by combining metallic and ceramic advantages like metal-doped hydroxyapatite, zinc-hydroxyapatite (ZnHA) was used as one of the materials tested in this study. Zinc is a suitable element for the combination of HA because it is one of the necessary elements in the human body, and it also helps to develop the skeletal system and growth. Moreover, the use of zinc as an ion to hydroxyapatite has been reported to encourage the formation of bone activity, bone growth, and curing in case of damage ${ }^{13)}$.

A good cranial implant is not only limited to its material; the implant design, fabrication, and skills of the surgeon also play an important role in making the 
cranioplasty procedure successful. An implant with a solid surface is less effective compared to a porous surface because a porous surface promotes bone ingrowth and it also enhances the bonding between the bone and the implant. The pore sizes between 240 and $730 \mu \mathrm{m}$ and even up to $1200 \mu \mathrm{m}$ displayed enough evidence for bone ingrowth ${ }^{14)}$. However, most researchers believed that the ideal pore size for bone ingrowth ranged from 100 to 400 $\mu \mathrm{m}^{15)}$. According to Itala et al. ${ }^{16)}$, the pore size diameter range from 50-125 $\mu \mathrm{m}$ also showed good bone ingrowth. Therefore, the ideal pore size of the porous implant for bone ingrowth has been still inexplicit so far.

Many researchers have studied the stress distribution and deformation on the implant by varying the implant materials, design, thickness, and shape; however, there is a lack of studies on pore sizes and ZnHA as one of the implant materials tested. Thus, the present study aimed to analyze the biomechanical behavior of the parietaltemporal implant with different materials and pore sizes by using finite element analysis. This study was focusing on three materials, include titanium (Ti6Al4V), hydroxyapatite (HA), and zinc-hydroxyapatite (ZnHA), and three different pore sizes of 600,900 , and $1200 \mu \mathrm{m}$.

\section{Materials and methodology}

\subsection{Development of the three-dimensional defective skull model}

A female, 15 years old patient was submitted to CT scanning due to the large cranial defect on the right parietal-temporal area. The 3D Gens Sdn. Bhd. provided the 245 CT scan images with a thickness of $1 \mathrm{~mm}$ in the DICOM format. Afterward, the Mimics 21.0 (Materialize NV, Leuven, Belgium) software was utilized to convert the two-dimensional (2D) images in DICOM format to the 3D defective skull model. The defective skull images underwent the segmentation operation with the Hounsfield unit of $226 \mathrm{HU}$ to $3071 \mathrm{HU}$. Then, the region grows and split mask technique were applied to remove the unnecessary part around the bone. Next, a clear view of the 3D defective skull model was generated by applying 3D calculation, smooth and wrap operation as shown in Fig. 1. It was then saved in the Standard Tessellation Language (STL) format.

\subsection{Reconstruction of a cranial implant}

The STL file from the previous stage (Fig. 2a) was loaded to 3-Matic 13.0 (Materialize NV, Leuven, Belgium) software to develop the implant constituent of the defect area. A smooth curve was drawn around the fracture site, close to the defect edge but in the low curvature region. (Fig. 2b). The sagittal sketch was created by selecting two extreme endpoints on the skull and adjusting it with interactive translate or rotate techniques to ensure the sagittal sketch was located at the middle of the skull (Fig. 2c). The cranial implant was developed using the mirror technique which the skull was duplicated and mirrored at the sagittal sketch (mid-plane) (Fig. 2d). After that, the coronal sketch was created by duplicating the sagittal sketch and rotating it 90 degrees with the enable snapping method to create the guiding line. (Fig. 2e).

Next, the skull information, mirrored anatomy, and defect curve were imported into the sketch before created the guiding curve. A spline feature was applied to generate the guiding curve drawn from the starting point to the ending point. The guiding curve must closely match the mirrored skull to obtain the actual shape of the skull (Fig. 2f). The surface construction operation was performed to generate the implant (Fig. 2g). The idea of the skull thickness at various areas around the defect edge was then obtained by randomly appointing six points around the fracture edge of the initial skull and applying the measure distance technique. The thickness of the implant was created by assigning the local thickness value on the surface contour of the implant using a variable offset tool (Fig. 2h). After that, the Boolean subtraction operation was performed between the defect skull and implant to get the smooth fit (Fig. 2i).

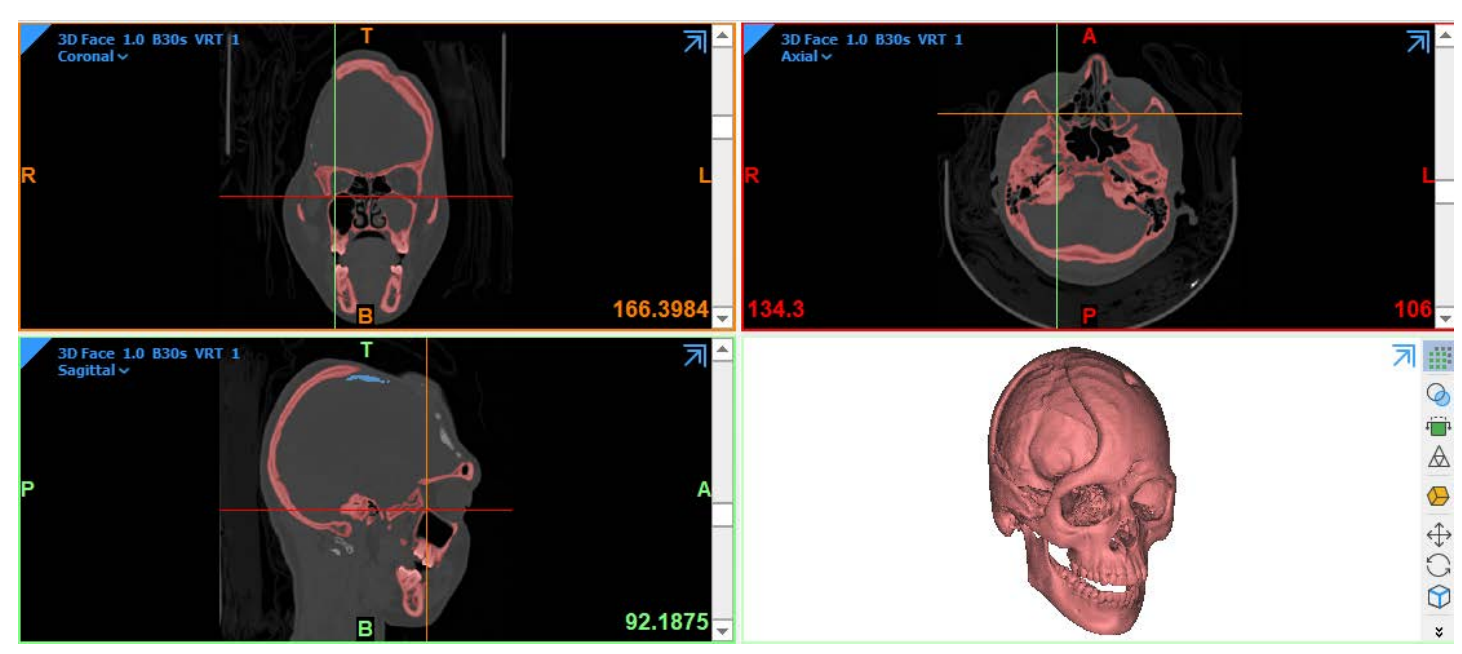

Fig. 1: The development of the 3D model of the right parietal-temporal defect using computed tomography images. 


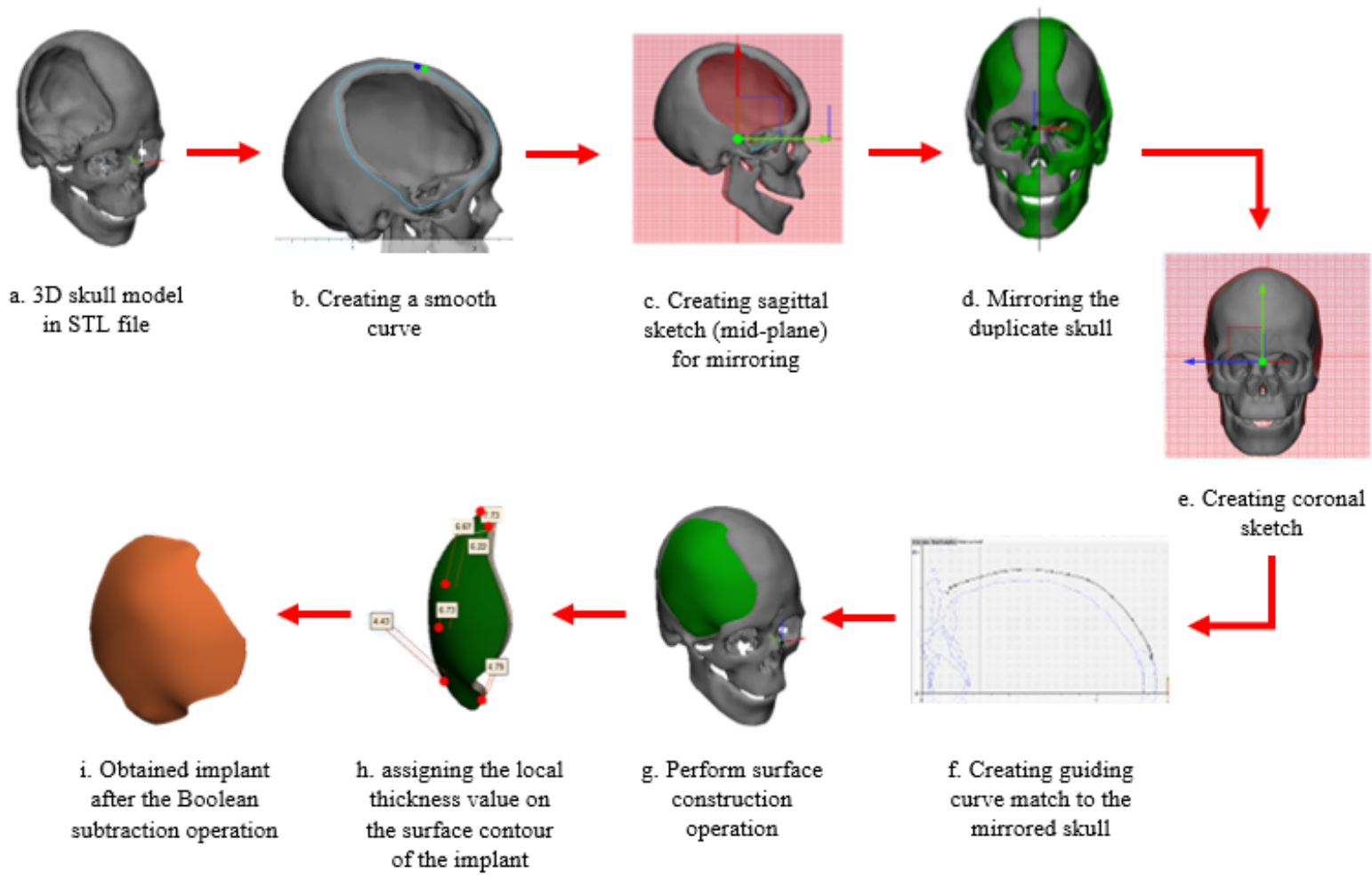

Fig. 2: Process of cranial implant reconstruction using 3-Matic software.

\subsection{Development of porous implant}

Before moving on to the next step, the implant from the previous phase was finished by eliminating any obstructing materials, combining the multiple surfaces on the sides, and smoothing the top and bottom contours. The process of removing the obstructing materials was needed to ensure the implant having a good fit. Moreover, the assembly between skull and implant was performed with the function of the non-manifold assembly. The triangular length of both skull and implant was set $6 \mathrm{~mm}$ and $4 \mathrm{~mm}$, respectively.

Next, the design process of the pore on the implant was started by firstly, a prism with six sides or known as hexagonal shape of diameter $600 \mu \mathrm{m}$ was created. Then, several points were marked on the implant, which indicated the location of the pore and the point-based pattern feature was utilized to generate the hexagonal shape attached at each selected point. Finally, the implant with the pore size of $600 \mu \mathrm{m}$, as illustrated in Fig. 3(a), was developed by applying Boolean subtraction between the original implant and the implant with the hexagonal shape attached. The design process was repeated by substituting the hexagonal pore structure's diameter of $600 \mu \mathrm{m}$ to 900 and $1200 \mu \mathrm{m}$. The implant with various pore sizes $(600,900$, and $1200 \mu \mathrm{m})$ and the skull model that has been undergone the assembly process was saved in STL format. The STL format describes only the surface of the model. Therefore, all model in STL format was sent to the Fusion 360 (Autodesk, California, United States) software to convert the surface model to the solid model and were saved in SAT format for the finite element analysis.

(a)

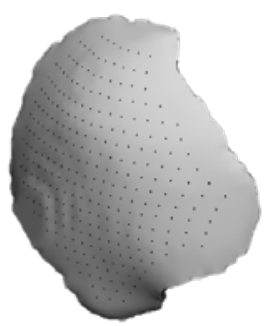

(b)
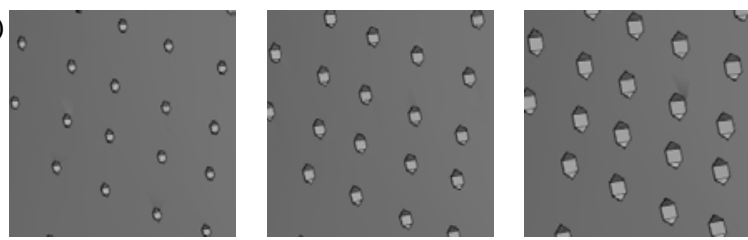

Fig. 3: (a) The porous implant (b) Close-up view of porous implant with pore size 600, 900 and $1200 \mu \mathrm{m}$ (from left to right).

\subsection{Finite element analysis}

The finite element analysis was conducted using Abaqus v2020 (Dassault Systèmes, Vélizy-Villacoublay, France) software. The implant of pore sizes 600, 900, and $1200 \mu \mathrm{m}$ were simulated with three different materials: HA, Ti6Al4V, and ZnHA. The material properties of the skull and implant were inputted as shown in Table 1 before proceeding with the analysis. 
Table 1. The material properties.

\begin{tabular}{|c|c|c|c|}
\hline Material & $\begin{array}{c}\text { Young's } \\
\text { Modulus } \\
\text { (GPa) }\end{array}$ & $\begin{array}{c}\text { Poisson's } \\
\text { Ratio }\end{array}$ & $\begin{array}{c}\text { Ultimate } \\
\text { Strength } \\
\text { (MPa) }\end{array}$ \\
\hline Bone & $15^{10)}$ & $0.3^{10)}$ & - \\
\hline $\begin{array}{c}\text { Titanium } \\
\text { (Ti6Al4V) }\end{array}$ & $110^{10)}$ & $0.3^{10)}$ & $950^{17)}$ \\
\hline $\begin{array}{c}\text { Hydroxyapatite } \\
\text { (HA) }\end{array}$ & $10^{18)}$ & $0.3^{18)}$ & $58^{8)}$ \\
\hline $\begin{array}{c}\text { Zinc } \\
\text { Hydroxyapatite } \\
\text { (ZnHA) }\end{array}$ & $6^{18)}$ & $0.3^{18)}$ & $168.9^{19)}$ \\
\hline
\end{tabular}

The implant and skull model was assumed to be linear, solid, and homogenous to make the analysis easier. The analysis was performed with the tetrahedral element and 1.6 global mesh size. The meshing size was determined by doing the convergence study to get an accurate result without taking a long time. The convergence study was carried out based on the quantity by varying the mesh sizes of the tetrahedral elements from 1.2 to 2.2, as illustrated in Fig. 4. A simple mechanical analysis was conducted on the implant by applying the same load value of $50 \mathrm{~N}$ at the middle of the implant and $2 \mathrm{kPa}(15 \mathrm{mmHg})$ at the internal surface of the implant for all mesh sizes.

The total number of elements for the implant model with pore sizes of 600,900 , and $1200 \mu \mathrm{m}$ were 412302 , 423965, and 434874, respectively. The implant was assembled with the skull, and the interface of the connection was assumed to be perfectly bonded by using tie constraints operation. As illustrated in Fig. 5, the skull was fixed at the bottom as the boundary condition. The loading of $50 \mathrm{~N}$ was applied at the center of the implant, which mimics the force acting on the skull when resting on a flat surface ${ }^{20}$. In addition, the intracranial pressure (ICP) of $2 \mathrm{kPa}(15 \mathrm{mmHg})$, which is a physiological value of ICP ${ }^{21)}$, was loaded at the internal surface of the skull ${ }^{20)}$. Both loadings were acting perpendicularly to the surface.

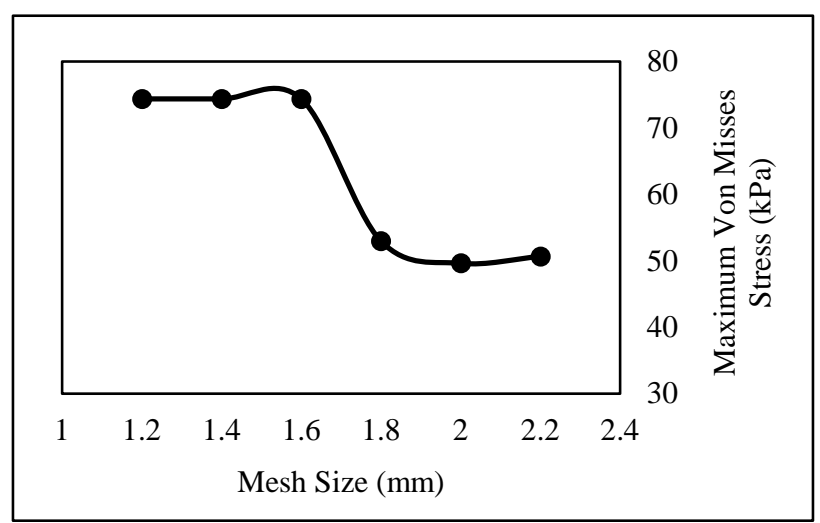

Fig. 4: The convergence study graph.

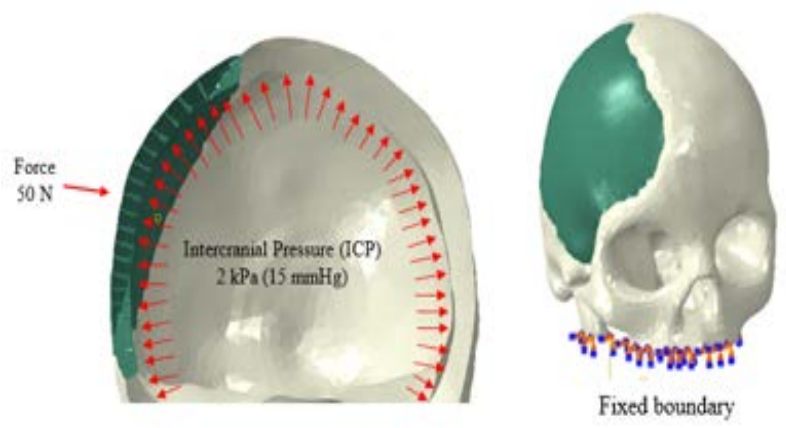

Fig. 5: Loading and boundary condition layout.

\section{Results}

\subsection{Stress distribution and deformation of the implant}

The stress distribution pattern on the implant with different materials and pore sizes configurations was presented in Fig. 6(a). It was seen that the stress distribution pattern at the lower region of the Ti6Al4V implant was higher than HA and ZnHA implant for all three pore sizes. Fig. 6(b) depicted the maximum Von Mises stress and displacement trend. It revealed that the maximum Von Mises stress for all materials decreased slightly from pore sizes $600 \mu \mathrm{m}$ to $900 \mu \mathrm{m}$ but increased dramatically from pore sizes $900 \mu \mathrm{m}$ and $1200 \mu \mathrm{m}$. By contrast, the maximum displacement increased steadily as the pore size increased. The maximum Von Mises stress of Ti6Al4V implant reached the highest value, which is $5.45 \mathrm{MPa}$ at the pore size $1200 \mu \mathrm{m}$, whereas ZnHA of pore size $900 \mu \mathrm{m}$ presented the lowest Von Mises stress (2.04 $\mathrm{MPa}$ ). When comparing the Ha and ZnHA implant, it was noticed that the ZnHA implant showed the lower value of maximum Von Mises stress for all pore sizes involved in the present study except for the implant with the diameter pore size of $600 \mu \mathrm{m}$, it displayed vice versa.

When considering the displacement result, Ti6Al4V shown the best compared to the HA and ZnHA implant. This is because the displacement result of the Ti6Al4V was relatively lower in comparison with the HA and ZnHA implant. The maximum displacement of HA material of pore size 600,900 , and $1200 \mu \mathrm{m}$ was $5.86 \mathrm{~mm}$, $5.92 \mathrm{~mm}$, and $6 \mathrm{~mm}$, respectively. In pore sizes aspects, for $\mathrm{ZnHA}$, the pore size of $1200 \mu \mathrm{m}$ (7.66 mm) displayed higher displacement as compared to the pore size of 600 $(7.44 \mathrm{~mm})$ and $900(7.53 \mathrm{~mm}) \mu \mathrm{m}$. For the Ti6Al4V implant, the maximum displacement increased uniformly from $4.32 \mathrm{~mm}$ to $4.36 \mathrm{~mm}$ with the increment of $0.02 \mathrm{~mm}$ for each pore size.

\subsection{Stress distribution and deformation of the skull}

Fig. 7(a) showed the stress distribution pattern around the bone-implant interface on the skull. From Fig. 7(a), it was observed that Ti6Al4V material had lower stress 
distribution around the bone-implant interface based on the color contour around the defect area compared to the HA and ZnHA implant. However, the higher maximum Von Mises stress for each pore size was found when Ti6Al4V was used as the material for the implant, as displayed in Fig. 7(b). This is because the maximum Von Mises stress was located near the boundary condition, not at the bone-implant interface. Fig. 7(b) presented the trend of maximum Von Mises stress and displacement of the skull based on pore sizes. Both graphs displayed the increase in pore sizes increased maximum Von Mises stress and displacement. From all cases, the highest maximum Von Mises stress was $0.863 \mathrm{MPa}$ showed by Ti6Al4V implant of pore size $1200 \mu \mathrm{m}$. Moreover, the
ZnHA with pore size $600 \mu \mathrm{m}$ possessed the lowest $(0.834$ $\mathrm{MPa})$ maximum Von Mises stress. The maximum Von Mises stress of HA for pore size 600, 900, and $1200 \mu \mathrm{m}$ was $0.836 \mathrm{MPa}$, $0.839 \mathrm{MPa}$, and $0.842 \mathrm{MPa}$, respectively.

Furthermore, Fig. 7(b) indicated the maximum displacement of pore size $600 \mu \mathrm{m}$ for Ti6Al4V, HA and ZnHA implant was $4.45 \mathrm{~mm}, 4.75 \mathrm{~mm}$, and $4.86 \mathrm{~mm}$, respectively. When compare the pore size of the $\mathrm{ZnHA}$ implant, it showed the pore size $600 \mu \mathrm{m}(4.86 \mathrm{~mm})$ had lower deflection, followed by pore size $900 \mu \mathrm{m}(4.87 \mathrm{~mm})$ and $1200 \mu \mathrm{m}$ (4.9 mm). In material aspects, Ti6Al4V displayed a lower deflection compared to the HA and ZnHA material with corresponding pore sizes.

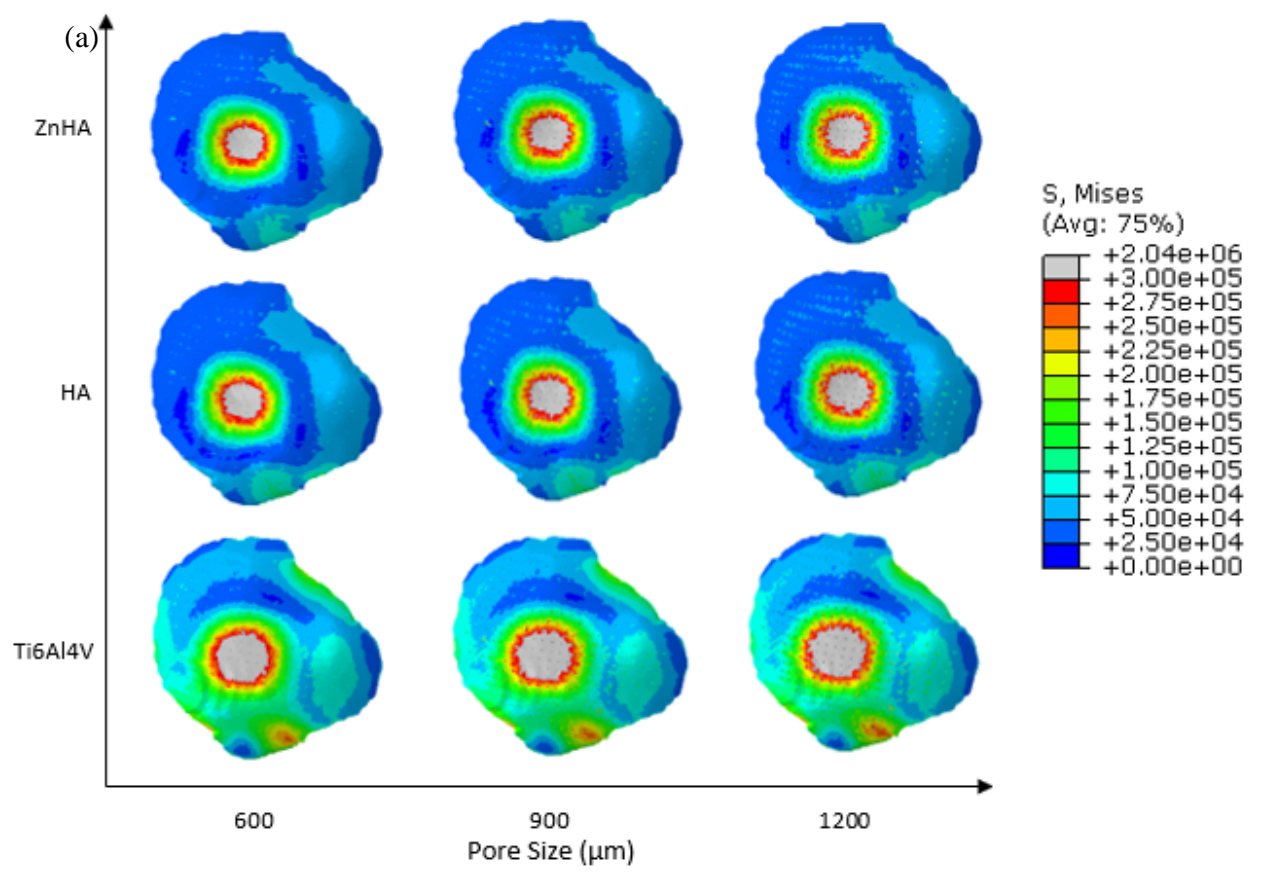

(b)
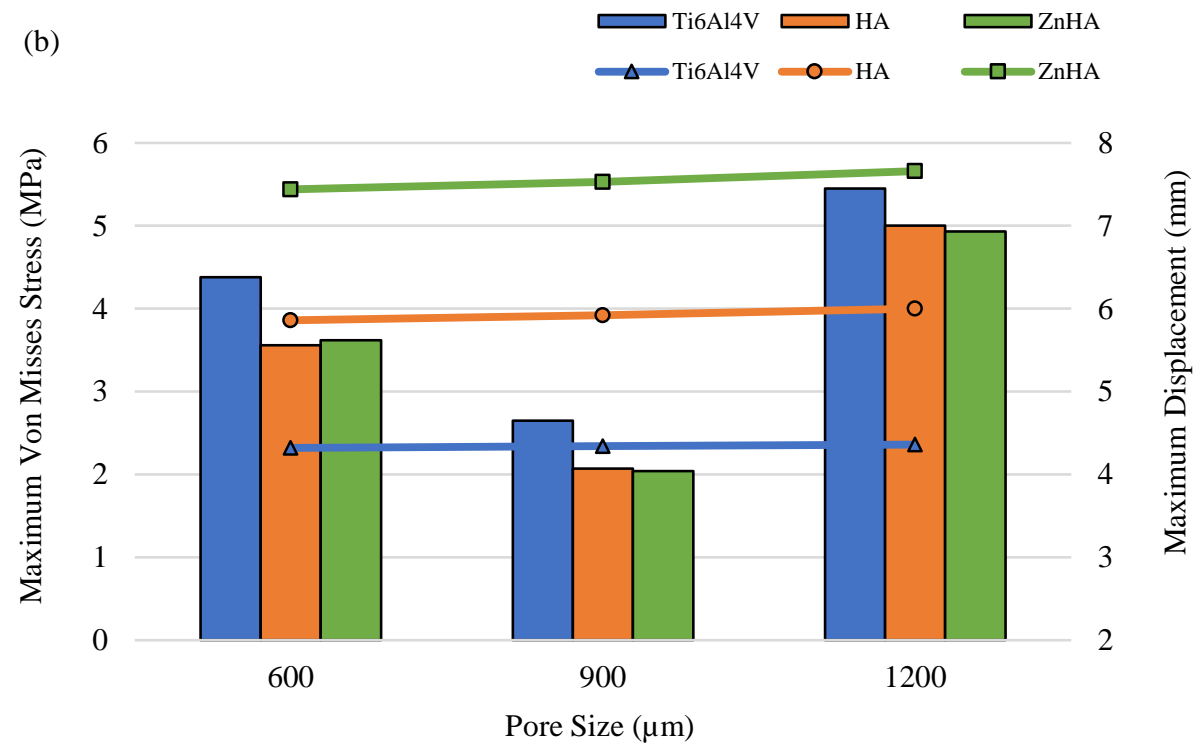

Fig. 6: The FEA results on the cranial implant with different material and pore size: (a) the stress distribution patterns and (b) the graph of maximum Von Mises stress (bar chart) and maximum displacement (line chart). 

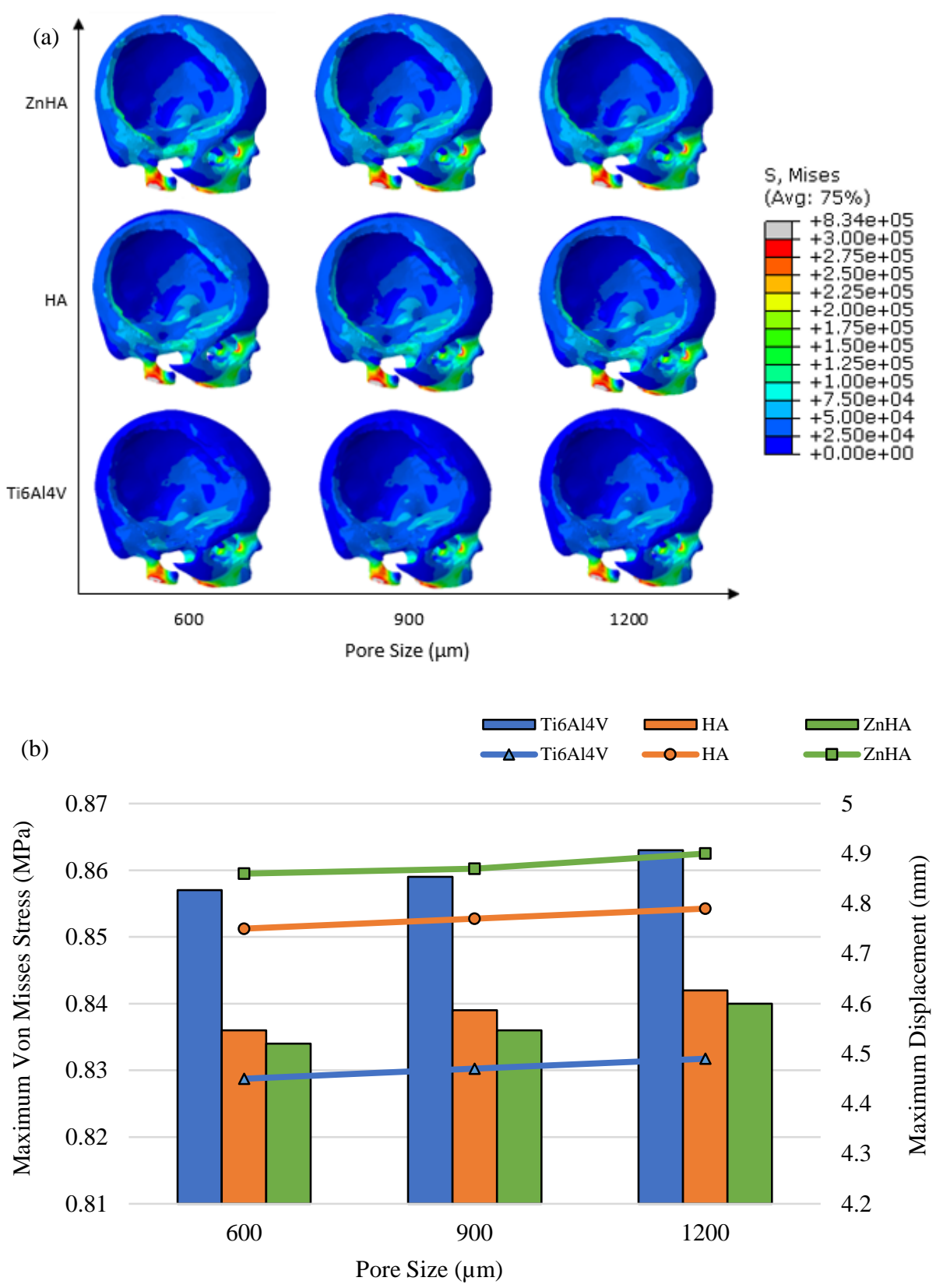

Fig. 7: The FEA results on the skull with different material and pore sizes: (a) the stress distribution patterns and (b) the graph of maximum Von Mises stress (bar chart) and maximum displacement (line chart).

\section{Discussion}

Nowadays, the FEA technique in biomechanics problems such as hip, knee, and craniomaxillofacial has been accepted widely ${ }^{22-27)}$. In the present study, the FEA technique was used to assess the biomechanical behavior of the right parietal-temporal implant. To be more specific, the biomechanical behavior in terms of mechanical stress and deformation of the implant and skull was assessed by varying the implant materials and pore sizes under the static loading. The convergence study has been done in this study to reduce time consumption and get an accurate result. It was done by changing the global mesh size of the implant range from $1.2 \mathrm{~mm}$ to $2.2 \mathrm{~mm}$ with an increment of $0.2 \mathrm{~mm}$. From Fig. 3, it was found that a mesh size of 1.6 and below showed a converged value of maximum Von Mises stress. Thus, the $1.6 \mathrm{~mm}$ mesh size was used in the entire study. Therefore, the results of the FEA analysis in this study are reliable.

From the result obtained in this study, the maximum Von Mises stress was primarily influenced by pore sizes; meanwhile, the material properties had the greatest influence on the implant's deformation. This result was revealed by Fig 6(b), when comparing HA to ZnHA implants (which have a low difference in Young's Modulus) of pore size $600 \mu \mathrm{m}$, the difference of maximum Von Mises stress was 0.06 MPa. In contrast, the difference of maximum Von Mises stress of HA implant between 
pore size $600 \mu \mathrm{m}$ and $900 \mu \mathrm{m}$ was $1.49 \mathrm{MPa}$. Furthermore, based on the deformation aspects, the difference of displacement value between HA and ZnHA implants of pore size $600 \mu \mathrm{m}$ was $1.58 \mathrm{~mm}$, which is more significant affecting the deformation. On the contrary, pore sizes of the implant have a lower significant effect on the deformation which the difference of displacement value between HA implant of pore size $600 \mu \mathrm{m}$ and $900 \mu \mathrm{m}$ was $0.06 \mathrm{~mm}$. This result is similar to the study conducted by Marcian et al. ${ }^{10)}$ where the implant material leads to a higher deformation than implant thickness. Moreover, compared to the PMMA and PEEK implant materials used in their study, the Ti6Al4V material illustrated the lowest displacement. Furthermore, as indicated in Fig 6(a), the maximum stress on all cases was located at the center of the implant where the static force was applied, which is in agreement with the work reported by Haen et al. ${ }^{28)}$.

The safety factor was considered in this study to determine which material and pore size of the implant is suitable to be used. As demonstrated in Fig. 8, it showed that all cases had a safety factor value of greater than one; thus, all designs of implants in this study were acceptable as they did not exceed the material's ultimate strength or known as the maximum stress that the material can resist before fracture. Ti6Al4V implant with a pore size of 900 $\mu \mathrm{m}$ possessed the highest safety factor (358.5) even though it exhibited higher maximum Von Mises stress than the HA and ZnHA implant. In addition, it also demonstrated the lowest deformation and good stress distribution around the defect area. Therefore, it can be declared that Ti6Al4V implant with a pore size of $900 \mu \mathrm{m}$ was the most suitable to be used.

Moreover, the ideal pore size for the cranial implant is still indefinite because there are conflicts between the previous study. Brie et al. ${ }^{29)}$ found that bone tissue only penetrates 18 to $43 \%$ of porous areas when the pore size range from 300 to $500 \mu \mathrm{m}$ was used. Meanwhile, Zheng et al. ${ }^{15)}$ reported in their study that the pore size of 100 to $400 \mu \mathrm{m}$ was ideal for bone ingrowth. In contrast to Zheng et al., Itala et al. ${ }^{16)}$ believed that pore size of 50 to $125 \mu \mathrm{m}$ displayed good bone ingrowth. However, pore size 900 $\mu \mathrm{m}$ that provides excellent results in this study, was included in the range of pore size stated by LopezHeredia $^{14)}$ that showed enough evidence for bone ingrowth.

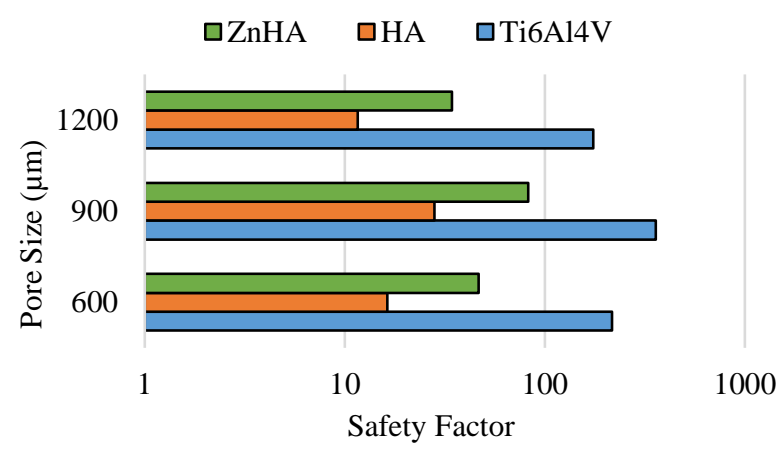

Fig. 8: The safety factor of all implant configurations.

\section{Conclusion}

In conclusion, the implant of the right parietal-temporal defect was successfully reconstructed and restored. The Ti6Al4V implant with a pore size of $900 \mu \mathrm{m}$ is the best because it showed the highest safety factor even though it exhibited the higher maximum Von Mises stress compared to HA and ZnHA implant. Moreover, the result of the FEA confirmed that the Ti6Al4V implant displayed excellent stress distribution around the defect area on the skull. Therefore, this study might greatly benefit the surgeon and engineer when designing the cranial implant.

\section{Acknowledgments}

This study was funded by the University Teknologi MARA and the Ministry of Higher Education, Malaysia under FRGS Grant, No. 600-IRMI/FRGS 5/3 (162/2019). We thank and acknowledge our partners from UiTM Cawangan Pulau Pinang for the technical supports and 3D Gens Sdn. Bhd. for providing the DICOM images, technical support and sharing their experience on cranioplasty project.

\section{References}

1) D. Sahoo, C. Deck, N. Yoganandan, and R. Willinger, "Development of skull fracture criterion based on real-world head trauma simulations using finite element head model," J. Mech. Behav. Biomed. Mater., $\quad 57 \quad 24-41 \quad$ (2016). doi:10.1016/j.jmbbm.2015.11.014.

2) D. Mohotti, P.L.N. Fernando, and A. Zaghloul, "Evaluation of possible head injuries ensuing a cricket ball impact," Comput. Methods Programs Biomed., $158 \quad 193-205 \quad$ (2018). doi:10.1016/j.cmpb.2018.02.017.

3) M.J. Bak, and T.D. Doerr, "Craniomaxillofacial fractures during recreational baseball and softball,” $J$. Oral Maxillofac. Surg., 62 (10) 1209-1212 (2004). doi:10.1016/j.joms.2004.06.034.

4) Z. Rossini, A. Franzini, I. Zaed, N. Zingaretti, F. Nicolosi, and B. Zanotti, "Custom-made porous hydroxyapatite cranioplasty in patients with tumor versus traumatic brain injury: a single-center case series," World Neurosurg., 138 e922-e929 (2020). doi:10.1016/j.wneu.2020.03.144.

5) V. Borger, P. Schuss, T.M. Kinfe, H. Vatter, and E. Güresir, "Decompressive craniectomy for stroke: early cranioplasty is a predictor for postoperative complications," World Neurosurg., 92 83-88 (2016). doi:10.1016/j.wneu.2016.04.113.

6) Y.H. Huang, T.M. Yang, T.C. Lee, W.F. Chen, and K.Y. Yang, “Acute autologous bone flap infection after cranioplasty for postinjury decompressive craniectomy,” Injury, 44 (1) 44-47 (2013). doi:10.1016/j.injury.2011.11.005.

7) K. Moiduddin, S. Darwish, A. Al-Ahmari, S. 
ElWatidy, A. Mohammad, and W. Ameen, "Structural and mechanical characterization of custom design cranial implant created using additive manufacturing," Electron. J. Biotechnol., 29 22-31 (2017). doi:10.1016/j.ejbt.2017.06.005.

8) D. Garcia-Gonzalez, J. Jayamohan, S.N. Sotiropoulos, S.H. Yoon, J. Cook, C.R. Siviour, A. Arias, and A. Jérusalem, "On the mechanical behaviour of peek and ha cranial implants under impact loading," J. Mech. Behav. Biomed. Mater., 69 (January) 342-354 (2017). doi:10.1016/j.jmbbm.2017.01.012.

9) M.T. Huang, P.K. Juan, S.Y. Chen, C.J. Wu, S.C. Wen, Y.C. Cho, M.S. Huang, H.H. Chou, and K.L. Ou, "The potential of the three-dimensional printed titanium mesh implant for cranioplasty surgery applications: biomechanical behaviors and surface properties,” Mater. Sci. Eng. C, 97 (August 2018) 412-419 (2019). doi:10.1016/j.msec.2018.11.075.

10) P. Marcián, N. Narra, L. Borák, J. Chamrad, and J. Wolff, "Biomechanical performance of cranial implants with different thicknesses and material properties: a finite element study,” Comput. Biol. Med., 109 (November 2018) 43-52 (2019). doi:10.1016/j.compbiomed.2019.04.016.

11) B.A. Khader, and M.R. Towler, "Materials and techniques used in cranioplasty fixation: a review," Mater. Sci. Eng. C, 66 315-322 (2016). doi:10.1016/j.msec.2016.04.101.

12) S. Aydin, B. Kucukyuruk, B. Abuzayed, S. Aydin, and G.Z. Sanus, "Cranioplasty: review of materials and techniques,” J. Neurosci. Rural Pract., 2 (2) 162-167 (2011). doi:10.4103/0976-3147.83584.

13) D. Lytkina, A. Gutsalova, D. Fedorishin, N. Korotchenko, R. Akhmedzhanov, V. Kozik, and I. Kurzina, "Synthesis and properties of zinc-modified hydroxyapatite," 1-12 (2020).

14) M.A. Lopez-Heredia, E. Goyenvalle, E. Aguado, P. Pilet, C. Leroux, M. Dorget, P. Weiss, and P. Layrolle, "Bone growth in rapid prototyped porous titanium implants,” J. Biomed. Mater. Res. - Part A, 85 (3) 664-673 (2008). doi:10.1002/jbm.a.31468.

15) J. Zheng, L. Chen, D. Chen, C. Shao, M. Yi, and B. Zhang, "Effects of pore size and porosity of surfacemodified porous titanium implants on bone tissue ingrowth," Trans. Nonferrous Met. Soc. China, 29 (12) 2534-2545 (2019). doi:10.1016/S10036326(19)65161-7.

16) A.I. Itala, H.O. Ylanen, C. Ekholm, K.H. Karlsson, and H.T. Aro, "Pore diameter of more than $100 \mu \mathrm{m}$ is not requisite for bone ingrowth in rabbits,” J. Biomed. Mater. Res., $58 \quad$ (6) 679-683 (2001). doi:10.1002/jbm.1069.

17) V. Phanindra Bogu, Y. Ravi Kumar, and A. Kumar Khanra, "Homogenous scaffold-based cranial/skull implant modelling and structural analysis-unit cell algorithm-meshless approach,” Med. Biol. Eng. Comput., 55 (11) 2053-2065 (2017). doi:10.1007/s11517-017-1649-3.

18) C.C. Negrila, M.V. Predoi, S.L. Iconaru, and D. Predoi, "Development of zinc-doped hydroxyapatite by sol-gel method for medical applications," Molecules, $23 \quad$ (11) 1-15 (2018). doi:10.3390/molecules23112986.

19) J. Pinc, J. Čapek, V. Hybášek, F. Průša, K. Hosová, J. Maňák, and D. Vojtěch, "Characterization of newly developed zinc composite with the content of $8 \mathrm{wt}$. \% of hydroxyapatite particles processed by extrusion," Materials (Basel)., $13 \quad$ (7) (2020). doi:10.3390/ma13071716.

20) N. Narra, A. Ridwan-pramana, P. Marcian, T. Forouzanfar, J. Wolff, and L. Borak, "Structural and mechanical implications of pmma implant shape and interface geometry in cranioplasty e a fi nite element study n b , libor bor a,” 1-11 (2015). doi:10.1016/j.jcms.2015.10.014.

21) C. Paper, J. Chamrad, N. Narra, and L. Borak, "Evaluating different shapes of cranial fixation miniplates using finite element method evaluating different shapes of cranial fixation mini-plates using finite element method,” (June) (2018). doi:10.1007/978-981-10-5122-7.

22) A.H. Abdullah, and M. Todo, "Effects of total hip arthroplasty on stress adaptation and bone remodeling in lower limbs," Evergreen, 2 (1) 6-11 (2015). doi:10.5109/1500422.

23) S.L.S. Chauhan, and S.C. Bhaduri, "Structural analysis of a four-bar linkage mechanism of prosthetic knee joint using finite element method," Evergreen, $7 \quad$ (2) 209-215 (2020). doi:10.5109/4055220.

24) M. Sharma, and M. Soni, “A musculoskeletal finite element study of a unique and customised jaw joint prosthesis for the asian populace,” Evergreen, 7 (3) 351-358 (2020). doi:10.5109/4068615.

25) J. Chamrad, and P. Marcia, "On the level of computational model of a human skull: a comparative study,” (July) (2018). doi:10.24132/acm.2018.385.

26) V.P. Bogu, Y.R. Kumar, and A.K. Khanara, "Modelling and structural analysis of skull/cranial implant: beyond mid-line deformities,” Acta Bioeng. Biomech., 19 (1) 125-131 (2017). doi:10.5277/ABB00547-2016-04.

27) S.S. Chauhan, "Kinematic and kinetic gait analysis of bilateral knee osteoarthritis and its effects on ankle and hip gait mechanics,” Evergreen, 7 (3) 359-365 (2020).

28) P. Haen, G. Dubois, P. Goudot, and T. Schouman, "Comparative finite element analysis of skull mechanical properties following parietal bone graft harvesting in adults,” J. Cranio-Maxillofacial Surg., $46 \quad$ (2) 329-337 (2018). doi:10.1016/j.jcms.2017.11.020.

29) J. Brie, T. Chartier, C. Chaput, C. Delage, B. Pradeau, 
F. Caire, M.P. Boncoeur, and J.J. Moreau, “A new custom made bioceramic implant for the repair of large and complex craniofacial bone defects," $J$. Cranio-Maxillofacial Surg., 41 (5) 403-407 (2013). doi:10.1016/j.jcms.2012.11.005. 